\title{
Speciation and distribution of arsenic and localization of nutrients in rice grains
}

\author{
E. Lombi ${ }^{1,2}$, K. G. Scheckel ${ }^{3}$, J. Pallon ${ }^{4}$, A. M. Carey ${ }^{5}$, Y. G. Zhu ${ }^{6}$ and A. A. Meharg ${ }^{5}$ \\ ${ }^{1}$ Department of Agriculture and Ecology, Faculty of Life Science, University of Copenhagen, Thorvaldsensvej 40, DK-1871 Frederiksberg C, Denmark; \\ ${ }^{2}$ Present address: Centre for Environmental Risk Assessment and Remediation, University of South Australia, Building X, Mawson Lakes Campus Mawson \\ Lakes, South Australia, SA-5095 Australia and CRC CARE, PO Box 486, Salisbury, South Australia 5106, Australia; ${ }^{3}$ National Risk Management Research \\ Laboratory, US Environmental Protection Agency, 5995 Centre Hill Avenue, Cincinnati, Ohio 45224, USA; ${ }^{4}$ Division of Nuclear Physics, Department of \\ Physics, Lund Institute of Technology, Lund University, PO Box 118, SE-221, Sweden; ${ }^{5}$ Institute of Biological and Environmental Sciences, University \\ of Aberdeen, Cruickshank Boulevard, St Machar Drive, Aberdeen, AB24 3UU, UK; ${ }^{6}$ Research Centre for Eco-environmental Sciences, Chinese Academy of \\ Sciences, Beijing 100085, China
}

Author for correspondence:

Enzo Lombi

Tel: +61883026267

Email: enzo.lombi@unisa.edu.au

Received: 26 February 2009

Accepted: 22 April 2009

New Phytologist (2009) 184: 193-201 doi: 10.1111/j.1469-8137.2009.02912.x

Key words: arsenic (As), micronutrients, particle induced $X$-ray emission (PIXE), rice grain, synchrotron.

\section{Summary}

- Arsenic (As) contamination of rice grains and the generally low concentration of micronutrients in rice have been recognized as a major concern for human health. Here, we investigated the speciation and localization of As and the distribution of (micro)nutrients in rice grains because these are key factors controlling bioavailability of nutrients and contaminants.

- Bulk total and speciation analyses using high-pressure liquid chromatography (HPLC)-inductively coupled plasma mass spectrometry (ICP-MS) and X-ray absorption near-edge spectroscopy (XANES) was complemented by spatially resolved microspectroscopic techniques ( $\mu$-XANES, $\mu$-X-ray fluorescence $(\mu-X R F)$ and particle induced X-ray emission (PIXE)) to investigate both speciation and distribution of $A s$ and localization of nutrients in situ.

- The distribution of As and micronutrients varied between the various parts of the grains (husk, bran and endosperm) and was characterized by element-specific distribution patterns. The speciation of As in bran and endosperm was dominated by As(III)-thiol complexes.

- The results indicate that the translocation from the maternal to filial tissues may be a bottleneck for As accumulation in the grain. Strong similarities between the distribution of iron $(\mathrm{Fe})$, manganese $(\mathrm{Mn})$ and phosphorus $(\mathrm{P})$ and between zinc $(\mathrm{Zn})$ and sulphur (S) may be indicative of complexation mechanisms in rice grains.

\section{Introduction}

Recently, rice was recognized as a major route of arsenic (As) exposure for humans (Heikens et al., 2007; Meharg et al., 2009). Several studies have indicated that, in populations not exposed to As-tainted water, rice consumption is the largest contributor to the dietary As intake (Tsuji et al., 2007; Mondal \& Polya, 2008). Rice also contributes significantly to the As exposure of populations living in areas where Ascontaminated groundwater is used to grow rice in paddy fields (Williams et al., 2007; Mondal \& Polya, 2008). For dietary reasons the groups more at risk appear to be Asian com- munities, infants and young children (Meharg et al., 2008) and possibly people following vegan and macrobiotic diets (Zhu et al., 2008).

In comparison with other cereal grains, baseline concentrations of As in rice are approx. 10-fold larger (Williams et al., 2007). Our current knowledge indicates that two factors are responsible for elevated concentrations of As in grain. First, As in paddy soils predominantly occurs in its reduced form (arsenite), which is more mobile than arsenate (Xu et al., 2008). Second, recent evidence shows that the uptake of arsenite by rice is mediated by the same transport system responsible for silicon (Si) uptake (Ma et al., 2008), with rice being a highly 
efficient Si-accumulating plant (Ma \&Yamaji, 2006). The study of Ma et al. (2008) indicates that the uptake of uncharged arsenite in rice mainly occurs through aquaglycerolporins responsible for Si uptake (i.e. LSi1). Another Si transporter (LSi2) was shown to be involved in the As transport to the shoot. However, the As metabolism in plants also plays a role in terms of its redistribution among the various organs. For example, methylated species are taken up rather inefficiently compared with inorganic species but seem to be translocated more efficiently (Raab et al., 2007). Because of the complexity of these processes the mechanisms responsible for As loading into the rice grains and its speciation and distribution within the grain are not fully understood. For example, the large majority of the information available on As distribution and speciation in rice is related to the analyses of powdered rice grains. To our knowledge, only one study has focused on the in situ speciation and distribution of As in rice grains (Meharg et al., 2008). In that study, we reported synchrotron $\mu$-X-ray fluorescence ( $\mu$-XRF) results showing that As was mainly localized in the outer regions of the grains (i.e. aleurone/pericarp or outer parts of the endosperm). However, identification of its exact localization was hampered by the fact that the rice grains were simply fractured before analyses. This resulted in elemental maps that were projections of all of the elements present in the samples in the specific path of the $\mathrm{X}$-ray beam. Furthermore, localization of lighter elements (such as $\mathrm{Si}$, phosphorus $(\mathrm{P})$ and sulphur $(\mathrm{S})$ ), which may provide insights into the mechanisms of As accumulation, was not possible using the synchrotron $\mu$-XRF beamline in the study. Finally, we observed a discrepancy between the speciation results obtained by high-pressure liquid chromatography (HPLC)-inductively coupled plasma mass spectrometry (ICP-MS) and $\mu$-X-ray absorption near edge spectroscopy ( $\mu$-XANES). Specifically, inorganic As determined by $\mu$-XANES was larger than that assessed using HPLC-ICP-MS. This could have been because the areas chosen for $\mu$-XANES investigation were not representative of the overall speciation of the grain.

In the present study we aimed to overcome the limitations of our previous investigation. To this end we developed a technique that allowed preparation of thin sections (without embedding in resin), which increased the quality of the elemental mapping. Furthermore, we complemented spatially resolved synchrotron analyses with 'bulk' XANES and particle induced X-ray emission (PIXE) analyses, which allows mapping of lighter elements (such as P, S and Si). Finally, we investigated the localization of micronutrients such as zinc $(\mathrm{Zn})$ and iron $(\mathrm{Fe})$ in the grains. Rice generally contains small concentrations of these nutrients, which is a potential human nutrition issue for rice-based diets. A detailed knowledge of the distribution of macronutrients and micronutrients provides indications on possible ligands controlling the bioavailability of important elements (such as $\mathrm{Fe}$ and $\mathrm{Zn}$ ). This knowledge may also be useful in order to optimize various procedures used to process rice grains (e.g. dehusking, milling, etc.).

\section{Materials and Methods}

\section{Sample sourcing and preparation}

The rice (Oryza sativa $\mathrm{L}$.) grain sample $(\mathrm{CH} 2 \mathrm{G})$ was sourced from an As-elevated region of Hunan, China. The sample comes from the Hengyang area which is affected by lead $(\mathrm{Pb})$ and $\mathrm{Zn}$ mining operations (Williams et al., 2009). Both 'bulk' and in situ analyses were conducted in order to assess the As distribution and speciation and the localization of nutrients in the grains.

For bulk analysis, the husk was manually separated from the bran and endosperm. The bran and endosperm (known also as polished or white rice) were then separated using a laboratory polisher (Retsch MM301, Düsseldorf, Germany) operating for $120 \mathrm{~s}$ at 1800 r.p.m. Husk, bran and endosperm were then finely ground using a laboratory ball mill.

For the reasons explained above, in situ analyses required preparation of thin sections (Lombi \& Susini, 2009). However, previous attempts to prepare thin sections of rice grains, without resin embedding, were unsuccessful as during sectioning the grains tends to pulverize (Meharg et al., 2008). Embedding of the grains was not considered as this may cause elemental redistribution and changes in As speciation. Therefore, a technique was developed that allowed thin sections to be prepared without resin embedding of the grains. For this the grains were first fractured with a razor blade, either longitudinally or transversely, in order to obtain a flat surface that was then glued to a metal support. The grains mounted in this way were then sliced using a vibrating blade microtome (VT1000 $S$; Leica). To prevent the sliced part of the sample from pulverizing during sectioning a piece of Kapton polyimide film (DuPont) was pressed on the top of the sample with the blade of the microtome cutting underneath. In this way, $70-\mu \mathrm{m}$ thick longitudinal sections and cross-sections were directly obtained on the Kapton tape and were ready for in situ analyses.

\section{'Bulk' arsenic speciation and element concentrations}

Total As concentrations were determined by ICP-MS (7500; Agilent Technologies, Santa Clara, CA, USA) after microwave digestion as described in Sun et al. (2008).

Arsenic speciation on the bulk samples was determined using two different techniques. The HPLC-ICP-MS technique was used to determine As speciation in extracts of husk, bran and endosperm of pulverized samples following the method described by Sun et al. (2008). Furthermore, As speciation was also measured on the pulverized samples by means of 'bulk' XANES since this technique minimizes the risk of artefacts during sample preparation or alteration during extraction. The XANES spectra were collected at Sector 20-ID (XOR/PNC) at the Advanced Photon Source (APS), Argonne National Laboratory (Argonne, IL, USA). The electron storage ring operated at $7 \mathrm{GeV}$ with a top-up fill status. The Sector 20 undulator beamline includes a liquid nitrogen cooled Si (111) 
New

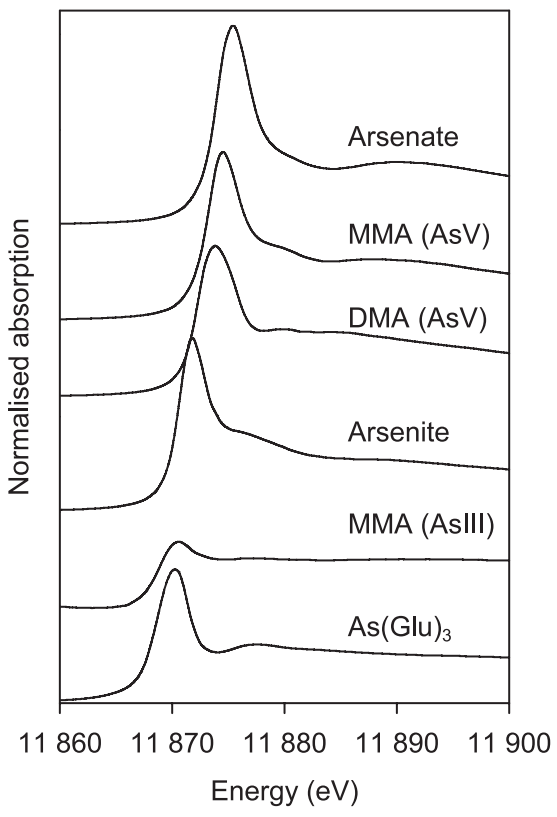

Fig. 1 Arsenic (As) X-ray absorption near edge spectroscopy (XANES) of standard compounds.

double crystal monochromator which was calibrated, in accordance with Smith et al. (2005), using the first inflection point of the gold $(\mathrm{Au}) \mathrm{L}_{\mathrm{III}}$ absorption edge $(11919 \mathrm{eV})$ for measurements at the As K-edge (11 $868 \mathrm{eV})$. Energy calibration of the XANES spectra was obtained by simultaneous measurement of a Au metal foil reference. The rice grain sections were mounted in a cryostat sample holder $\left(-20^{\circ} \mathrm{C}\right)$ to hinder beam induced artefacts. The XANES spectra were collected in fluorescence mode with a solid-state 13-element $\mathrm{Ge}(\mathrm{Li})$ detector. Arsenic standards were analysed as powders (diluted in boron nitride) and included: arsenite $\left(\mathrm{NaAsO}_{2}\right)$, arsenate $\left(\mathrm{NaH}_{2} \mathrm{AsO}_{4}\right)$, monomethylarsonic acid (MMA containing $\mathrm{As}(\mathrm{V})$ ) and dimethylarsinic acid (DMA, containing As $(\mathrm{V})$ ). The spectrum for As(III) MMA and As-glutathione $\left(\mathrm{As}(\mathrm{Glu})_{3}\right)$ were kindly provided the Environmental Sciences Group of the Royal Military College of Canada and details can be found in Smith et al. (2005). The spectra of the standard compounds are reported in Fig. 1. The XANES data (average of three scans) of the samples were background corrected (automatically) and analysed by linear combination fitting (LCF) using Athena (Ravel \& Newville, 2005). In this regard the normalized spectra were fitted in the range $-20 \mathrm{eV}$ to $+30 \mathrm{eV}$ from the absorption edge, the standards were not constrained to use a single $\mathrm{E}_{0}$ shift, the weighting factors were constrained to be between 0 and 1 and the weights were forced to sum to 1 . It should be emphasized here that the LCF approach is not free of uncertainties and limitations. First of all the correctness of the LCF is affected by the, often a priori, choice of the standards that will be used in the fitting procedure (Beauchemin et al., 2002). Therefore, the results obtained will depend on the choices of the standards that will be used. For example in this study $\mathrm{As}(\mathrm{Glu})_{3}$ was used as a surrogate for As-phytochelatin and As-metallothionein complexes but it cannot be excluded that if the spectra of these complexes were used in the LCF procedure, different results could have been obtained. Therefore, the results reported here should be interpreted with caution until a direct determination of these complexes is conducted.

\section{In situ analyses}

Laterally resolved XRF analysis of the thin sections was conducted at Sector 20 of the APS using both the bending magnet (BM) and the insertion device (ID) beamlines. The $\mu$-XRF maps were collected using a spot size of 5-10 $\mu \mathrm{m}$ and step sizes ranging from 5 to $25 \mu \mathrm{m}$ depending on the size of the area mapped and the resolution required. Speciation of As at selected microspots was probed by $\mu$-XANES at beamline 20-ID and the data analysed as described earlier for 'bulk' XANES spectra.

Although very powerful in terms of resolution and sensitivity, the synchrotron techniques based on hard X-rays cannot be used to map the distribution of lighter elements such as $\mathrm{Si}, \mathrm{S}$ and $P$ which may influence the distribution and speciation of As and micronutrients. Therefore, a second set of experiments was conducted, at Lund University Nuclear Microprobe Laboratory, using $\mu$-particle induced X-ray emission ( $\mu$-PIXE) to assess the distribution of these macronutrients. This microbeam line (Shariff et al., 2005; Elfman et al., 2005) uses a 3 MV single-ended electrostatic accelerator (NEC), a two-stage magnetic quadrupole doublet focusing lens system (Oxford OM-52, Oxford Microbeam OM-52, Oxford, UK) and an annular eight element Germanium X-ray array detector (Canberra, Meriden, CT, USA) for PIXE measurements (Shariff et al., 2004). A proton beam of $2.5 \mathrm{MeV}$ was focused to a spot size of $c .5 \mu \mathrm{m}$ at a current of typically $300 \mathrm{pA}$ (Pallon et al., 2007). In this case, the part of the samples that was left over from the sectioning procedure described above was used for the analysis. This choice was made because PIXE is inherently a surface analysis in comparison with synchrotron XRF and as such a flat topography is needed to obtain good quality elemental maps. The samples were C-coated before PIXE analyses to avoid surface charging.

\section{Results}

Total As concentration and As speciation in powdered samples

The total As concentration and the As speciation, determined by HPLC-ICP-MS, in bran and endosperm for this sample were previously reported by Sun et al. (2008). Here the data is complemented with the total As concentration and speciation in the husk. Total As concentrations in the powdered samples significantly increased (aNOVA, $P<0.001$ ) from the endosperm (white or polished rice) to the bran and husk (Table 1). 
Table 1 Total concentration and speciation of arsenic (As) in rice husk, bran and endosperm by high-pressure liquid chromatography-inductively coupled plasma mass spectrometry (HPLC-ICP-MS)

\begin{tabular}{llllllll}
\hline Grain fraction & $\begin{array}{l}\text { Total As } \\
\left(\mu \mathrm{g} \mathrm{g}^{-1}\right)\end{array}$ & $\begin{array}{l}{[\mathrm{DMA}]} \\
\left(\mu \mathrm{g} \mathrm{g}^{-1}\right)\end{array}$ & $\begin{array}{l}{[\mathrm{MMA}]} \\
\left(\mu \mathrm{g} \mathrm{g}^{-1}\right)\end{array}$ & $\begin{array}{l}{[\mathrm{As}(\mathrm{III})]+[\mathrm{As}(\mathrm{V})]} \\
\left(\mu \mathrm{g} \mathrm{g}^{-1}\right)\end{array}$ & $\begin{array}{l}\text { Organic As } \\
(\%)\end{array}$ & $\begin{array}{l}\text { Inorganic As } \\
(\%)\end{array}$ & $\begin{array}{l}\text { Not quantified As } \\
(\%)\end{array}$ \\
\hline Endosperm & 0.54 & 0.19 & - & 0.17 & 36 & 32 & 32 \\
Bran & 6.24 & 0.11 & 0.032 & 3.47 & 2 & 56 & 42 \\
Husk & 12.42 & 0.07 & 0.026 & 7.90 & 1 & 64 & 35 \\
\hline
\end{tabular}

Percentages are calculated on the total As values. Each sample was analysed in duplicate, the average value is presented.

The 'not quantified' fraction was calculated by dividing the sum of all the recovered species by the total As in the grain, multiplied by 100 . The sum of species does not necessarily equate to extraction efficiency as some arsenic may be lost during column separation.

DMA, dimethylarsinic acid; MMA, monomethylarsonic acid.

Table 2 Relative proportion (\%) of arsenic (As) species in rice husk, bran and endosperm as assessed by X-ray absorption near-edge spectroscopy (XANES)

\begin{tabular}{lllllllll}
\hline Grain fraction & {$[\mathrm{DMA}]$} & {$[\mathrm{MMA}](\mathrm{As}(\mathrm{III}))$} & {$\left[\mathrm{As}(\mathrm{Glu})_{3}\right]$} & {$[\mathrm{As}(\mathrm{III})]$} & {$[\mathrm{As}(\mathrm{V})]$} & Organic As \% & Inorganic As \% & Goodness of fit $\left(\chi^{2}\right)$ \\
\hline Endosperm & 27.2 & - & 55.6 & 18.4 & 1.5 & 26 & 74 & 0.33 \\
Bran & 26.1 & - & 52.9 & 12.9 & 13.3 & 25 & 75 & 0.76 \\
Husk & 15.8 & 30.6 & 12.9 & 20.3 & 20.3 & 46 & 54 & 0.57
\end{tabular}

Goodness of fit $\chi^{2}=\Sigma((\text { fit }- \text { data }) / \varepsilon)^{2} /\left(N_{\text {data }}-N_{\text {components }}\right)$ is the reduced $\chi^{2}$ statistic. Here $\varepsilon$ is the estimated uncertainty in the normalized XANES data. This parameter is calculated over $N_{\text {data }}$ points (99) between starting $E$ and ending E used for XANES fitting ( -20 to $30 \mathrm{eV}$ from the As edge), and $N_{\text {components }}$ is the number of components in the fit (in this case 6 ). The percentage of inorganic and organic species was calculated by dividing the proportion of the individual species by the sum of the proportion of all the species, multiplied by 100.

DMA, dimethylarsinic acid; MMA, monomethylarsonic acid.

Arsenic speciation in the powdered fractions of the rice grains where analysed by HPLC-ICP-MS and XANES. The former required extraction of the As before separation and quantification of the As species. The results indicate that the recovery was not complete and $32-42 \%$ of the total As remained unaccounted for with this approach (Table 1). The large majority of the As extracted was found to be present as inorganic species. Only in the endosperm did organic As species, in particular DMA, account for a large portion (36\%) of the total As.

The XANES spectra are reported in Fig. 2 and the results of the linear combination fitting in Table 2. This analysis revealed that in the endosperm and bran the dominant form of As species was similar to $\mathrm{As}(\mathrm{Glu})_{3}$. It should be noted here that in the grains the As(III)-thiolate complex are probably in the form of As-phytochelatin or As-metallothionein (Raab et al., $2004,2005)$. As $(\mathrm{Glu})_{3}$ is simply an analogue of these species that is often used as As-thiolate standard spectra (Smith et al., 2005; Meharg et al., 2008). We ultimately consider the Asthiolate complexes as inorganic as these complexes are readily labile under oxidized conditions (such as those occurring during digestion). Consequently, in these two grain fractions approximately one-quarter of the As could be assigned to organic As species. By contrast, in the husk inorganic and organic species contributed equally to the total As concentration (Table 2).

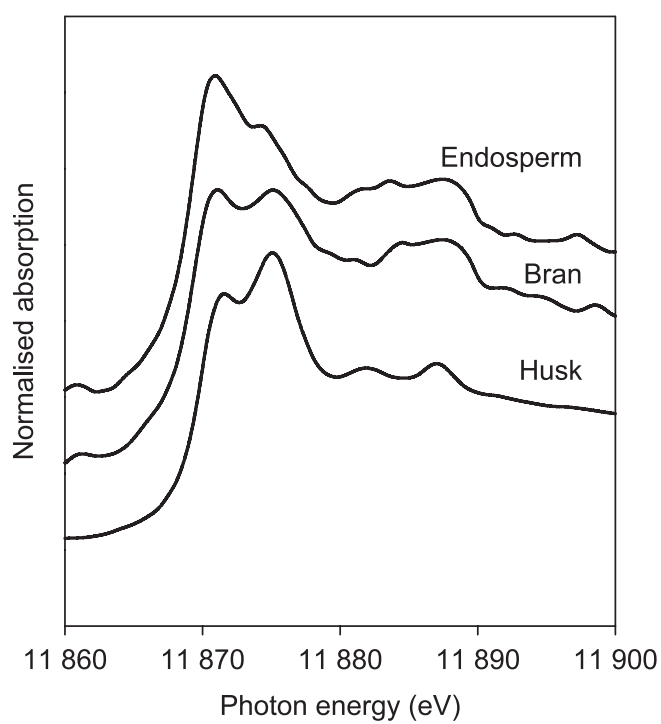

Fig. 2 Bulk arsenic (As) X-ray absorption near-edge spectroscopy (XANES) of husk, bran and endosperm of rice grains.

\section{Distribution and local speciation of As}

The distribution of As in a cross-section of a rice grain is shown in Fig. 3. It is evident that As is mainly localized in a 
New
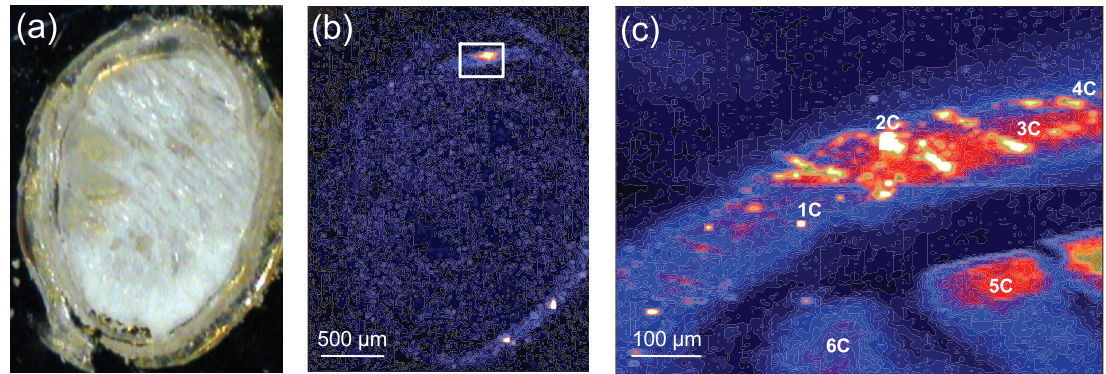

Fig. 3 Arsenic (As) X-ray fluorescence (XRF) elemental map of a cross-section of the rice sample (ventral side on top). The numbers in the As map refer to the positions where $\mu$-X-ray absorption near edge spectroscopy ( $\mu$-XANES) spectra were collected (these spectra are reported in Fig. 4). The colour is in arbitrary units with the black and white corresponding to the lowest and highest relative concentration, respectively. The XRF signals for map (b) were collected at the bending magnet (BM) beamline at 20- $\mu \mathrm{m}$ steps. The (c) map (which is the rectangular area shown in (b) was collected using the insertion device (ID) beamline at $5-\mu \mathrm{m}$ steps.

specific area on the periphery of the grain, between the husk and the endosperm. A close up of this area shows that high concentrations of As seem to be present in various tissues (e.g. aleurone and outer parts of the endosperm). It is interesting to note that this area of As accumulation corresponds to the position of the ovular vascular trace. The $\mu$-XANES spectra for As, collected at specific points as reported in Fig. 3, are shown in Fig. 4 (dashed lines). These results highlight the high spatial variability of As, not only in terms of distribution, but also in terms of speciation. For example, the main As species present in the $1 \mathrm{C}$ spot are arsenite and $\mathrm{As}(\mathrm{Glu})_{3}(30 \%$ and $65 \%$, respectively). By contrast, the analyses of the spectrum collected in the 2C spot shows a dominance of oxidized species with arsenate, DMA and As(V)MMA accounting for $32 \%, 21 \%$ and $31 \%$ of the total As, respectively. Finally, the $3 \mathrm{C}$ spectrum shows a much more balanced presence of $\mathrm{As}(\mathrm{V})$ : As(III) species (c. 40:60\%).

The distribution and local speciation of As were also investigated in a cross-section of the grain that included the germ or embryo. In this case, the map showing the localization of As is dominated by the large concentration in the husk (Fig. 5). However, it is possible to discern a larger concentration of As in the embryo in comparison with inner parts of the endosperm. The $\mu$-XANES spectra collected at selected spot across this section are reported in Fig. 4 (continuous lines). As already discussed, even in this case a large variability in As XANES spectra is discernible.

\section{Distribution of nutrients}

The same longitudinal section analysed at Sector 20-ID to assess As distribution (as reported in Fig. 5) was also analysed at the bending magnet beamline (Sector 20-BM) to collect whole grain distribution of nutrients. The sensitivity at 20-BM is much lower than that available at beamline 20-ID and for this reason As distribution across the whole grain could not be attained. Figure 6 shows the distribution of $\mathrm{Cu}, \mathrm{Fe}, \mathrm{Mn}$ and $\mathrm{Zn}$ as investigated using synchrotron XRF. High concentrations

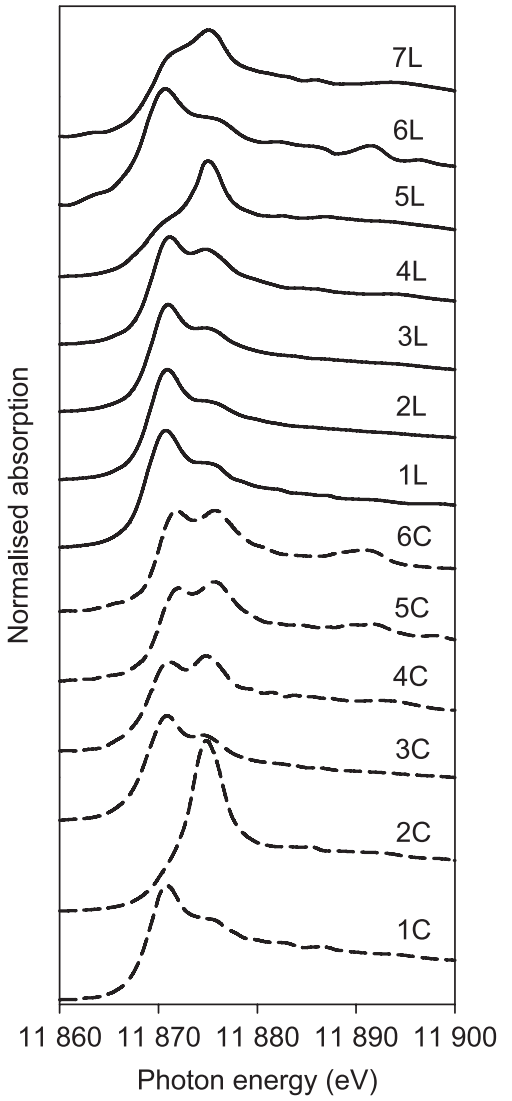

Fig. 4 Arsenic (As) $\mu$-X-ray absorption near-edge spectroscopy $(\mu$-XANES) spectra from cross $(C)$ and longitudinal $(L)$ rice grain sections. The positions on the sections where the analyses were conducted are reported in Figs 3 and 5.

of all the elements were observed in some region of the husk. However, the distribution of these nutrients varied considerably in the other parts of the grain. Zinc was mainly found in the central part of the embryo which likely corresponds to the plumule. Very interestingly in the case of $\mathrm{Zn}$, and possibly also of $\mathrm{Cu}$, its concentration decreased gradually from the 


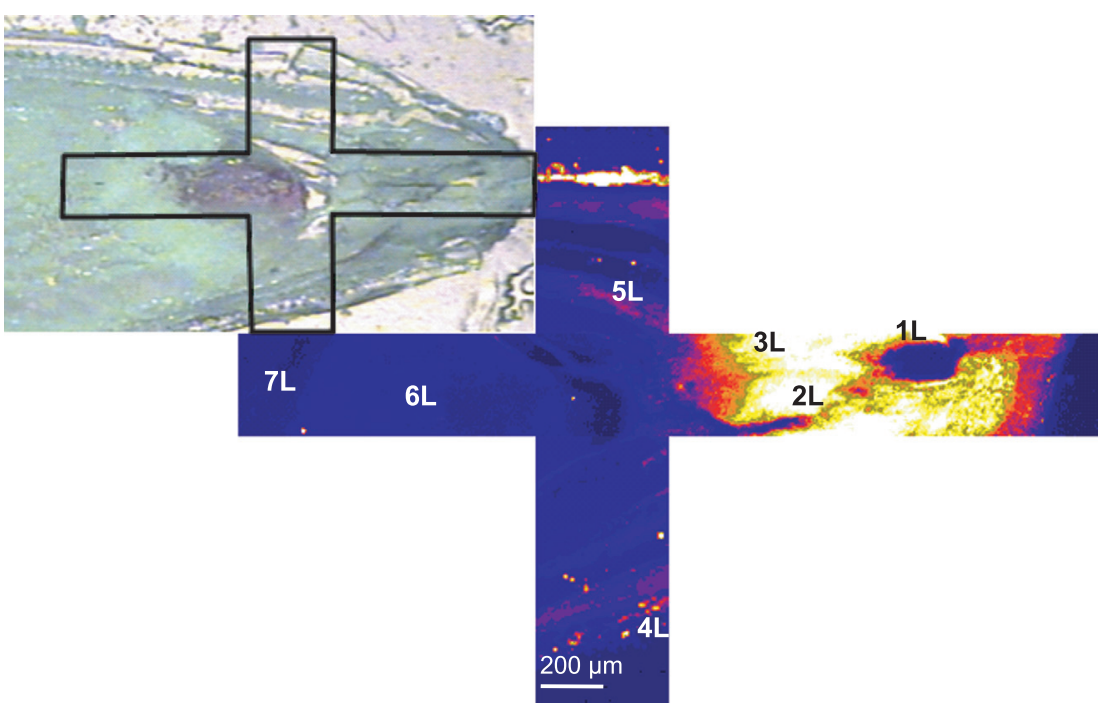

Fig. 5 Arsenic (As) X-ray fluorescence (XRF) elemental map of a longitudinal section of the rice sample. The numbers in the As map refer to the positions where $\mu$-X-ray absorption near-edge spectroscopy ( $\mu$-XANES) spectra were collected (these spectra are reported in Fig. 4). The colour is in arbitrary units with the black and white corresponding to the lowest and highest relative concentration. XRF signals were collected at the insertion device (ID) beamline at $5 \mu \mathrm{m}$ steps.
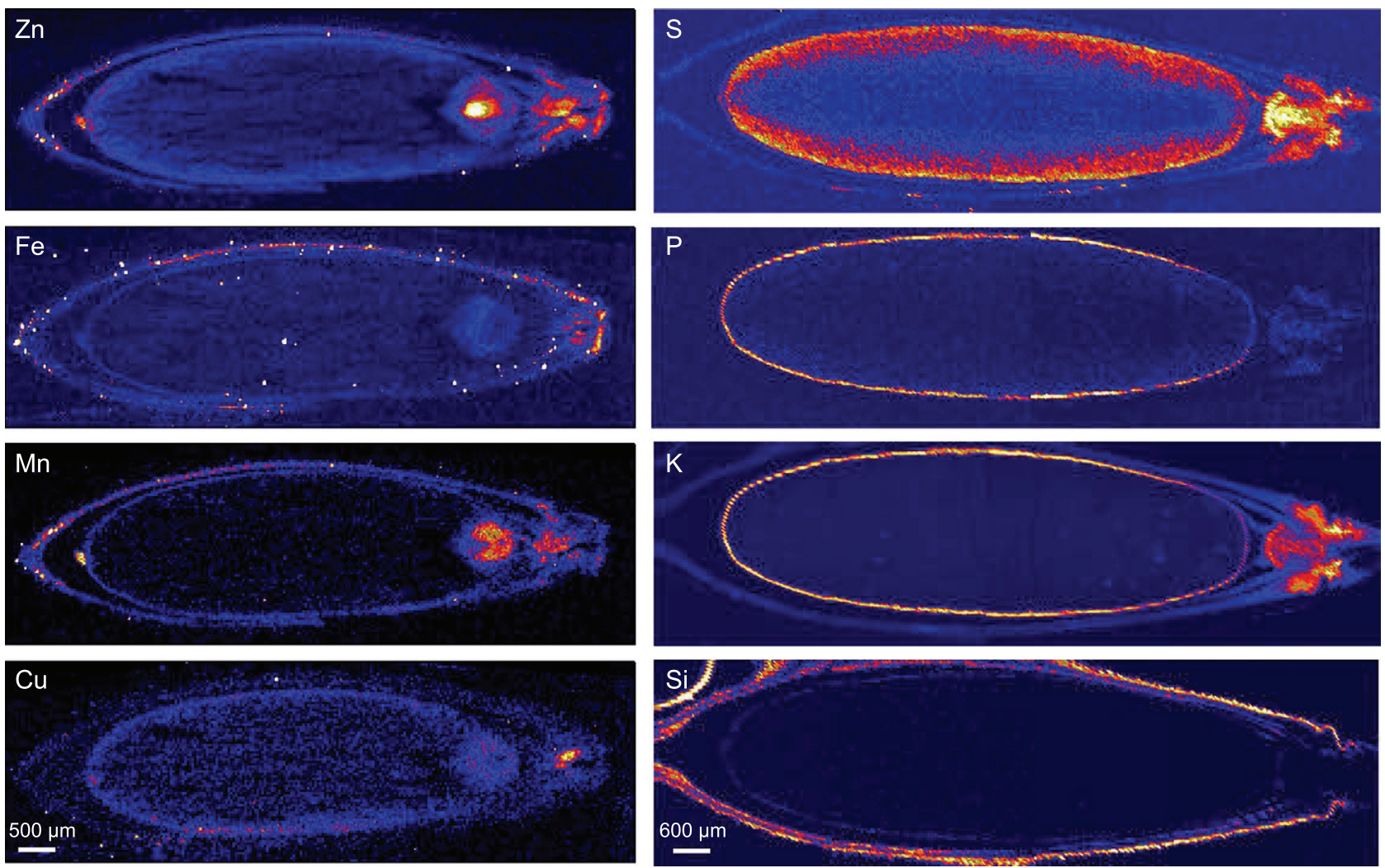

Fig. 6 Elemental maps of a longitudinal section of the rice sample. Synchrotron X-ray fluorescence (XRF) was used to collect the zinc (Zn), iron $(\mathrm{Fe})$, manganese $(\mathrm{Mn})$ and copper $(\mathrm{Cu})$ maps while sulphur $(\mathrm{S})$, phosphorus $(\mathrm{P})$, potassium $(\mathrm{K})$ and silicon (Si) maps were collected using particle induced X-ray emission (PIXE). The colour is in arbitrary units with the black and white corresponding to the lowest and highest relative concentration. Maps were collected at $25-\mu \mathrm{m}$ step size.

aleurone/pericarp and outer parts of the endosperm to the interior of the endosperm. By contrast, $\mathrm{Mn}$ and Fe were very much localized in the aleurone/pericarp region with a sharp change in concentration in the exterior parts of the endosperm. Manganese was also found to be highly concentrated in the embryo but with a different pattern from that observed for $\mathrm{Zn}$.

The distribution of K, P, S and Si were analysed by PIXE (Fig. 6). In this case, the sample used did not include the embryo. Interestingly, the $S$ distribution followed closely the 
pattern observed for $\mathrm{Zn}$ with a clear gradient in concentration from the external region into the central part of the endosperm. By contrast, $\mathrm{P}$ and $\mathrm{K}$ distribution appeared more similar to that of Fe and Mn. Finally, Si distribution was strikingly different with the majority of the element observed in the external parts of the husk (palea and lemna).

\section{Discussion}

Recently we reported the speciation and distribution of As in white and brown rice (Meharg et al., 2008). In that first report we were able to assess the local speciation of As and its distribution in fractured grains. However, the interpretation of the results was limited by the fact that the synchrotron techniques used were hampered by the variable thickness of the samples and no 'bulk' XANES results were reported. These limitations have been overcome in the present study which also considers the distribution of macro and micronutrients.

The results of the bulk analyses confirmed earlier reports that rice bran contains greater concentrations of As than the polished rice (Ren et al., 2006; Rahman et al., 2007; Sun et al., 2008). We also observed a dramatic decrease in As concentration from the husk surrounding the grain to the grain itself (Table 1). This difference, which was previously observed by Signes et al. (2008), is probably related to the way nutrients, contaminants and photosynthetates are distributed within the different organs. The large concentration of As in the husk probably derives from the xylematic transport of this contaminant. By contrast, accumulation of photosynthetates and minerals (including contaminants) in the seed occurs primarily through the phloem because seeds are largely nontranspiring tissues (Tanaka et al., 2007). The bran comprises some maternal tissues such as the ovular vascular system as well as filial tissues consisting of the aleurone layer, embryo and some endosperm. The filling of the seeds is reported to occur through unloading from the phloem into the nucellar tissue followed by uploading into the aleurone layer (Krishnan \& Dayanandan, 2003). Therefore, the larger concentrations present in the bran fraction compared with the polished rice may have two possible causes. First, there could be a physiological barrier in the unloading and uploading process responsible for the transfer of As from the maternal tissues (ovular vascular system, either phloem or xylem elements) to the filial tissues (aleurone). Second, As, as with many other elements, could accumulate preferentially in the protein-rich aleurone and embryo tissues although, because of the lateral resolution of the XRF technique, an accumulation in the outer parts of the endosperm cannot be excluded. Our synchrotron XRF results indicate that possibly both these mechanism occur. Figure 3 shows a large accumulation of As in correspondence of the ovular vascular trace. This finding corroborates the results reported by Meharg et al. (2008) who showed As accumulation to occur in a small area on the surface of the grain. This bottleneck in translocation from the maternal to the filial tissue needs to be further investigated to assess whether different As species cross this barrier with different efficiency. The difference in As speciation between husk and bran/ endosperm may point in this direction (Table 2). However, XRF mapping of a longitudinal grain section (Fig. 5) also suggests that the As concentration in the embryo region is greater than in the endosperm suggesting that As also preferentially accumulates in protein and nutrient rich parts of the grain. However, we should point out that with the technique we used here it is difficult to distinguish between the aleurone/ pericarp and the outer parts of the endosperm. Further research with enhanced lateral resolution is needed to ascertain the distribution of As between closely located tissues in the grain.

Arsenic speciation was conducted using both XANES and HPLC-ICP-MS. Comparison of the results obtained by laterally resolved and 'bulk' XANES showed significant differences (Fig. 4). This finding agrees with the consideration that while microbeam techniques provide an indication of the separate species present in the sample they are unable to provide an accurate assessment of their proportions in the whole sample (Lombi \& Susini, 2009). We found that $\mu$-XANES analysis showed a high degree of variability among the areas investigated. Similarly, the comparison of As speciation between 'bulk' XANES and the results obtained by HPLC-ICP-MS showed some discrepancies. However, in this case, the percentage of inorganic As species, as assessed by the two techniques, yielded similar results indicating that inorganic As represented a significant proportion of the total As (Tables 1, 2). Furthermore, DMA (with arsenic in its oxidized state) appears to be the main organic species independent of the technique used to assess As speciation. These results are in line with previous published work (Heitkemper et al., 2001; Williams et al., 2005; Zavala et al., 2008). The discrepancies between the results obtained with the two techniques can be attributable to the partial extraction of As before HPLC-ICPMS analyses (Table 1). It is possible, as suggested by Mir et al. (2007), that the species composition of the unextracted As is substantially different from the extracted phases analysed by HPLC-ICP-MS. Interestingly, XANES analysis revealed large differences between As speciation in the husk and the bran/ endosperm. This supports the suggestion made earlier that the source of As in these tissues may be different (i.e. xylem vs phloem). In the bran and endosperm the major As species identified by XANES were DMA and $\mathrm{As}(\mathrm{Glu})_{3}$. However, the latter is not observable through routine HPLC-ICP-MS analysis because of dissociation of the complex during extraction and analysis. The presence of As(III) complexed by thiol groups, most likely phytochelatins, has been reported in other plants (Pickering et al., 2000; Schmoger et al., 2000). However, to our knowledge, this is the first report showing the presence of As(III)-thiolate complexes in rice grains.

The distribution of macronutrients and micronutrients in husk, bran and endosperm was substantially different depending on the element considered. Concentrations of all micronutrients 
appeared to be large in the embryo regions even though the local distribution within the embryo varied between elements. Among the micronutrients, $\mathrm{Fe}$ and $\mathrm{Mn}$ were mainly found to be located, in addition to the embryo, in the husk and aleurone/ pericarp layers (Fig. 6). This distribution was similar to that observed for major nutrients such as $\mathrm{P}$ and $\mathrm{K}$ (although analysis of the embryo for these elements is not available). Phosphorus in the endosperm is reportedly in the form of phytin and nucleic acids (c. 40\% each), by contrast, phytin accounts for c. $90 \%$ in bran (McCall et al., 1953). Therefore, it is likely that $\mathrm{Fe}$ is present as phytate and as such it would have a low availability (Bohn et al., 2008). By contrast, $\mathrm{Zn}$ and S distribution is not limited to the aleurone/pericarp area but extends into the endosperm (Fig. 6). This suggests that $\mathrm{Zn}$ may be complexed by $-\mathrm{SH}$ groups, such as those present in phytochelatins and metallothionein. Production of phytochelatins in plants exposed to cadmium $(\mathrm{Cd})$ and $\mathrm{Zn}$ has been identified as a possible detoxification mechanism (Grill et al., 1985) but a possible role in $\mathrm{Zn}$ complexation in cereal grains remains to be investigated. In any case, the distribution of $S$ in the endosperm supports the XANES speciation, which indicates a large proportion of As to be complexed by thiol ligands. The distribution of $\mathrm{Si}$ is strikingly different from that of other elements. This element is highly concentrated in the outer layers of the husk. This distribution is in line with previous observations that in rice leaves $\mathrm{Si}$ deposited beneath the cuticle to form a cuticle-Si double layer (Ma \& Yamaji, 2006). This may be related to the fact that $\mathrm{Si}$ polymerizes when concentrations exceed $2 \mathrm{~mm}$. Conversely, this finding may indicate that while the uptake and root to shoot translocation of As(III) and $\mathrm{Si}$ are mediated by the same transporters (Ma et al., 2008), the distribution and accumulation mechanisms in the rice grains may be under a different control.

In conclusion, our study reveals striking differences in As distribution and speciation among husk, bran and endosperm. The large As concentration in the bran is probably the result of localization of the As along the ovular vascular system and accumulation in the embryo. This should be considered because rice bran is widely used as a food additive and as a 'premier health food product' (Sun et al., 2008). We reported for the first time, to our knowledge, that As in the bran and endosperm is dominated by As(III)-thiol complexes which has to be interpreted in view of their bioavailability upon ingestion. Previous studies have focused on the bioavailability of MMA, DMA arsenate and arsenite (Juhasz et al., 2006). Unfortunately, information in regard to the bioavailability of As(III)-thiol complexes is not available. However, considering that these complexes represent a significant part of the As in the grain this aspect should be investigated. Our results also indicate that the passage from the maternal to filial tissues may be a bottleneck for As accumulation in the grain. Finally, we showed strong similarities between the distribution of $\mathrm{Fe}$, $\mathrm{Mn}$ and $\mathrm{P}$ and between $\mathrm{Zn}$ and $\mathrm{S}$. This may indicate that these important micronutrients may be complexed by different ligands in rice grains even though direct investigation of their speciation is required.

\section{Acknowledgements}

The PNC/XOR facilities at the Advanced Photon Source, and research at these facilities, are supported by the US Department of Energy - Basic Energy Sciences, a major facilities access grant from NSERC, the University of Washington, Simon Fraser University and the Advanced Photon Source. Use of the Advanced Photon Source is also supported by the US Department of Energy, Office of Science, Office of Basic Energy Sciences, under Contract DE-AC02-06CH11357. We express our sincerest gratitude to Dr Paula Smith of the Royal Military College of Canada for providing arsenic reference spectra. The USEPA through its Office of Research and Development funded and managed a portion of the research. It has not been subject to Agency review and, therefore, does not necessarily reflect the views of the Agency. No official product endorsement should be inferred.

\section{References}

Beauchemin S, Hesterberg D, Beauchemin M. 2002. Principal component analysis approach for modeling sulfur K-XANES spectra of humic acids. Soil Science Society America Journal 66: 83-91.

Bohn L, Meyer AS, Rasmussen SK. 2008. Phytate: impact on environment and human nutrition. A challenge for molecular breeding. Journal of Zhejiang University-Science B 9: 165-191.

Elfman M, Pallon J, Auzelyte V, Kristiansson P, Malmqvist K, Nilsson C, Shariff A, Wegdén M. 2005. The Lund Nuclear Microprobe sub-micron set-up. Part III: sample stage, optical imaging and detector configuration in the experimental chamber. Nuclear Instruments and Methods in Physics Research Section B: Beam Interactions with Materials and Atoms 231: 14-20.

Grill E, Winnacker EL, Zenk MH. 1985. Phytochelatins - the principal heavy-metal complexing peptides of higher plants. Science 230: 674-676.

Heikens A, Panaullah GM, Meharg AA. 2007. Arsenic behaviour from groundwater and soil to crops: impacts on agriculture and food safety. Reviews of Environmental Contamination and Toxicology 189: 43-87.

Heitkemper DT, Vela NP, Stewart KR, Westphal CS. 2001. Determination of total and speciated arsenic in rice by ion chromatography and inductively coupled plasma mass spectrometry. Journal of Analytical Atomic Spectrometry 16: 299-306.

Juhasz AL, Smith E, Weber J, Rees M, Rofe A, Kuchel T, Sansom L, Naidu R. 2006. In vivo assessment of arsenic bioavailability in rice and its significance for human health risk assessment. Environmental Health Perspectives 114: 1826-1831.

Krishnan S, Dayanandan P. 2003. Structural and histochemical studies on grain-filling in the caryopsis of rice (Oryza sativa L.). Journal Bioscience 28: 455-469.

Lombi E, Susini J. 2009. Synchrotron-based techniques for plant and soil science: opportunities, challenges and future perspectives. Plant and Soil 320: 1-35.

Ma JF, Yamaji N. 2006. Silicon uptake and accumulation in higher plants. Trends Plant Science 11: 392-397.

Ma JF, Yamaji N, Mitani N, Xu XY, Su YH, McGrath SP, Zhao FJ. 2008. Transporters of arsenite in rice and their role in arsenic accumulation in rice grain. PNAS 105: 9931-9935.

McCall ER, Jurgens JF, Hoffpauir CL, Pons WA, Stark SM, Heinzelman DC, Cirino VO, Murray MD. 1953. Composition of rice. Influence of 
New

variety and environment on physical and chemical composition. Journal Agriculture Food Chemistry 1: 998.

Meharg AA, Lombi E, Williams PN, Scheckel KG, Feldmann J, Raab A, Zhu YG, Islam R. 2008. Speciation and localization of arsenic in white and brown rice grains. Environmental Science Technology 42: 1051-1057.

Meharg AA, Williams PN, Adomako E, Lawgali YY, Deacon D, Villada A, Cambell RCJ, Sun G, Zhu YG, Feldmann J et al. 2009. Geographical variation in total and inorganic arsenic content of polished (white) rice. Environmental Science Technology. doi: 10.1021/es802612a

Mir KA, Rutter A, Koch I, Smith P, Reimer KJ, Poland JS. 2007. Extraction and speciation of arsenic in plants grown on arsenic contaminated soils. Talanta 72: 1507-1518.

Mondal D, Polya DA. 2008. Rice is a major exposure route for arsenic in Chakdaha block, Nadia district, West Bengal, India: a probabilistic risk assessment. Applied Geochemistry 23: 2987-2998.

Pallon J, Wallander H, Hammer E, Arteaga Marrero N, Auzelyte V, Elfman M, Kristiansson P, Nilsson C, Olsson PA, Wegdén M. 2007. Symbiotic fungi that are essential for plant nutrient uptake investigated with NMP. Nuclear Instruments and Methods in Physics Research Section B 260: 149-152.

Pickering IJ, Prince RC, George MJ, Smith RD, George GN, Salt DE. 2000. Reduction and coordination of arsenic in Indian mustard. Plant Physiology 122: 1171-1177.

Raab A, Feldmann J, Meharg AA. 2004. The nature of arsenicphytochelatin complexes in Holcus lanatus and Pteris cretica. Plant Physiology 134: 1113-1122.

Raab A, Feldmann J, Schat H, Meharg AA. 2005. Uptake, translocation and transformation of arsenate and arsenite in sunflower (Helianthus annuus): formation of arsenic-phytochelatin complexes during exposure to high arsenic concentrations. New Phytologist 168: 551-558.

Raab A, Williams PN, Meharg A, Feldmann J. 2007. Uptake and translocation of inorganic and methylated arsenic species by plants. Environmental Chemistry 4: 197-203.

Rahman MA, Hasegawa H, Rahman MM, Rahman MA, Miah MA. 2007. Accumulation of arsenic in tissues of rice plant (Oryza sativa L.) and its distribution in fractions of rice grain. Chemosphere 69: 942-948.

Ravel B, Newville M. 2005. ATHENA, ARTEMIS, HEPHAESTUS: data analysis for X-ray absorption spectroscopy using IFEFFIT. Journal of Synchrotron Radiation 12: 537-541.

Ren X-L, Liu Q-L, Wu D-X, Shu Q-Y. 2006. Variations in concentration and distribution of health-related elements affected by environmental and genotypic differences in rice grains. Rice Science 13: 170-178.

Schmoger MEV, Oven M, Grill E. 2000. Detoxification of arsenic by phytochelatins in plants. Plant Physiology 122: 793-801.

Shariff A, Kristiansson P, Auzelyte V, Elfman M, Malmqvist K, Nilsson C, Pallon J, Wegdén M. 2004. Characterization of a new large area HPGe
X-ray detector for low beam current application. Nuclear Instruments and Methods in Physics Research Section B: Beam Interactions with Materials and Atoms 219: 494-498.

Shariff A, Nilsson C, Auzelyte V, Elfman M, Kristiansson P, Malmqvist K, Pallon J, Wegdén M. 2005. The Lund Nuclear Microprobe sub-micron set-up. Part II: beam line, focusing system and scanning. Nuclear Instruments and Methods in Physics Research Section B: Beam Interactions with Materials and Atoms 231: 7-13.

Signes A, Mitra K, Burlo F, Carbonell-Barrachina AA. 2008. Effect of two different rice dehusking procedures on total arsenic concentration in rice. European Food Research and Technology 226: 561-567.

Smith PG, Koch I, Gordon RA, Mandoli DF, Chapman BD, Reimer KJ 2005. X-ray absorption near-edge structure analysis of arsenic species for application to biological environmental samples. Environmental Science Technology 39: 248-254.

Sun GX, Williams PN, Carey AM, Zhu YG, Deacon C, Raab A, Feldmann J, Islam RM, Meharg AA. 2008. Inorganic arsenic in rice bran and its products are an order of magnitude higher than in bulk grain. Environmental Science Technology 42: 7542-7546.

Tanaka K, Fujimaki S, Fujiwara T, Yoneyama T, Hayashi H. 2007. Quantitative estimation of the contribution of the phloem in cadmium transport to grains in rice plants (Oryza sativa L.). Soil Science Plant Nutrition 53: 72-77.

Tsuji JS, Yost LJ, Barraj LM, Scrafford CG, Mink PJ. 2007. Use of background inorganic arsenic exposures to provide perspective on risk assessment results. Regulatory Toxicology and Pharmacology 48: 59-68.

Williams PN, Lei M, Sun G, Huang Q, Lu Y, Deacon C, Meharg AA, Zhu YG. 2009. Occurrence and partitioning of cadmium, arsenic and lead in mine impacted paddy rice: Hunan, China. Environmental Science Technology 43: 637-642.

Williams PN, Price AH, Raab A, Hossain SA, Feldmann J, Meharg AA. 2005. Variation in arsenic speciation and concentration in paddy rice related to dietary exposure. Environmental Science Technology 39: 55315540.

Williams PN, Raab A, Feldmann J, Meharg AA. 2007. Market basket survey shows elevated levels of As in South Central US processed rice compared to California: consequences for human dietary exposure. Environmental Science Technology 41: 2178-2183.

Xu XY, McGrath SP, Meharg AA, Zhao FJ. 2008. Growing rice aerobically markedly decreases arsenic accumulation. Environmental Science Technology 42: 5574-5579.

Zavala YJ, Gerads R, Gurleyuk H, Duxbury JM. 2008. Arsenicin rice: II. Arsenic speciation in USA grain and implications for human health. Environmental Science Technology 10: 3861-3866.

Zhu YG, Williams PN, Meharg AA. 2008. Exposure to inorganic arsenic from rice: a global health issue? Environmental Pollution 154: $169-171$ 